\title{
Elastic Turbulence Influences and Convective Heat Transfer Within a Miniature Viscous Disk Pump
}

\author{
Daniel Copeland ${ }^{1}$, Chong Ren ${ }^{1}$, Mengying $\mathrm{Su}^{1}$, Phil Ligrani ${ }^{2}$ \\ ${ }^{1}$ Propulsion Research Center, Department of Mechanical and Aerospace Engineering, \\ University of Alabama in Huntsville, Huntsville 35899 USA \\ ${ }^{2}$ Corresponding Author, Eminent Scholar in Propulsion, Professor of Mechanical and \\ Aerospace Engineering, Propulsion Research Center, Department of Mechanical and \\ Aerospace Engineering, University of Alabama in Huntsville, Huntsville 35899 USA \\ pm10006@uah.edu, 1-256-824-5173
}

\begin{abstract}
Elastic turbulence is employed within the present investigation to enhance convective heat transfer at very small scales and at very low Reynolds numbers. A miniature viscous disk pump or VDP is utilized to investigate flow and heat transfer, where the latter are based upon energy balance measurements which utilize the mixed-mean temperature at the inlet and outlet of the viscous disk pump passage. The overall heat transfer rate is determined based upon a constant surface temperature thermal boundary condition, and upon a log-meantemperature difference approach. The VDP operates at rotation speeds of 500 RPM, 1000 RPM, 1500 RPM, 1800 RPM, and 2000 RPM, which produce overall shear rates across the flow cross section of $146.051 / \mathrm{s}, 292.11 / \mathrm{s}, 438.151 / \mathrm{s}, 525.781 / \mathrm{s}$, and $584.21 / \mathrm{s}$. A channel depth of $640 \mu \mathrm{m}$ is employed. Elastic turbulence is induced by adding polyacrylamide to water solutions with 65 percent sucrose by mass. Significant enhancements of mixing and transport are observed, which are associated with the onset and development of elastic turbulence. Such behavior is verified, relative to an increased viscosity Boger fluid, using flow visualization results, rheometer viscosity variations with shear rate, and increases of overall magnitudes of convective heat transfer coefficient, which are augmented by as high as 240 percent. These comparisons are assessed relative to the Newtonian Boger fluid (which generally does not change viscosity as shear rate varies) at the same rotation speed, shear rate, flow passage height, and inlet temperature. As polymer concentration increases, elastic turbulence effects become more pronounced, and heat transfer coefficient magnitudes increase. This occurs such that Nusselt number ratios are strongly correlated with the meansquare magnitude of scalar temperature fluctuations at the outlet of the VDP. As a result, remarkable heat transfer coefficient enhancements due to elastic turbulence are demonstrated.
\end{abstract}

\section{Key words}

Elastic turbulence, micro-scale-flow, elasticity transition, thermal transport, heat transfer. 


\section{Introduction}

Various micro-scale devices have been investigated during recent decades, which generally operate at very low Reynold numbers. However, enhancements of convective heat transfer are a challenge to implement at such microscopic scales. The present investigation considers the use of elastic turbulence to enhance the fluid mixing, thermal transport, and heat transfer at very low Reynold numbers within such arrangements.

Elastic turbulence is excited by non-linear mechanical stresses, without significant inertial effects, at low Reynold numbers. The non-linear mechanical properties of the polymer solution generally lead to flow mixing and chaotic motions, referred as the Weissenberg instability [1]. When managed in an appropriate fashion, such polymer additives can lead to sharp growth in local elastic stress magnitudes, and local and global transition to elastic turbulence. Growth of local stresses depends upon experimental configuration, shear rate, polymer type, polymer concentration, and other parameters. The stress growth then stretches the polymer, leading to local secondary flow, increased mixing, and chaotic fluid motions [1]. This phenomenon is most often observed when the Weissenberg number is greater than an onset value, which depends upon polymer type, polymer concentration, experimental configuration, and other parameters.

A variety of different configurations are employed in recent investigations. For example, Grosiman and Steinberg [1] describe elastic instability generated within the viscoelastic fluid which augments mixing and transport within curved channels. Nashie et al. [2] numerically consider aspects of diffusion and flow behavior within a circular body of revolution. Observed are spatial chaos due to non-linear dynamics, which is linked to increased mixing and diffusion. Berti and Boffetta [3] and Berti et al. [4] consider elastic turbulence using twodimensional Kolmogorov flow. Their results show viscoelastic flows which demonstrate increasing mixing features and complexity with very small inertial non-linearity. Schiamberg et al. [5] describe experimental results which show sets of secondary flows with negligible inertial effects for flow between parallel plates. Li et al. [6] create chaotic fluid in microchannels with viscoelastic surfactant solutions at very low Reynold numbers. According to these investigators, elastic turbulence is induced by the viscoelasticity of the solution when strain is applied by curvilinear streamlines.

Experiments which consider the fluid mechanics and heat transfer behavior of viscoelastic aqueous polymer solutions in channel flow are described by Hartnett and Kostic [7] and by Hartnett [8]. For turbulent and laminar flows, such viscoelastic fluids show high heat transfer coefficients which are due to secondary motions, which are tied to unequal 
normal stresses within the viscoelastic fluids. Numerical investigations are described by Zhang et al. [9,10] which address connections between elastic turbulence and enhancement of local flow mixing. Abed et al. [11], and Whalley et al. [12] describe enhancements in flow mixing from elastic turbulence which often result in enhancements of convective heat transfer rates, when compared for the same configuration and same experimental conditions. Of these investigations, Abed et al. [11] experimentally consider convective heat transfer and fluid flow within a square cross-section serpentine channel with both polymeric viscoelastic fluids, and with constant-viscosity Newtonian Boger solutions as a basis of comparison. According to these investigators, convective heat transfer is enhanced by as much as 380 percent for higher polymer solutions and 200 percent for low polymer concentrations. Another recent investigation which considers elastic turbulence with heat transfer is described by Traore et al. [13]. Results show an increase in heat transfer efficiency within a von Karman flow with elastic turbulence, which illustrates efficient transport of heat in fluid media at low Reynolds numbers.

Within the present investigation, a miniature viscous disk pump (VDP) $[14,15]$ is utilized for experimental study of the effects of elastic turbulence with heat transfer. The experiment is undertaken using a viscoelastic solution with polyacrylamide, and 65 percent sucrose. Used as a basis of comparison is an increased-viscosity Newtonian Boger fluid (which generally does not change viscosity as shear rate varies), which is created with sucrose, but without any type of added polymer. Comparisons between the two types of fluids are generally undertaken at the same rotation speed, shear rate, flow passage height, and inlet temperature. Because such Boger fluids are elastic, with a constant viscosity that is independent of shear rate [16], associated results show distinctive different results, relative to elastic turbulence flows. With the present VDP arrangement, the flow passage height is $640 \mu \mathrm{m}$, and rotation speed, $\Omega$, ranges from 100 RPM to 2000 RPM. Heat transfer measurements are based upon energy balance considerations, which utilize the mixed-mean temperature at the inlet and outlet of the viscous disk pump passage. The overall heat transfer rate is determined based upon a constant surface temperature thermal boundary condition, and upon a log-meantemperature difference approach. The thermal boundary conditions at the side walls of the VDP passage are maintained at constant temperature, and whereas the rotating disk is adiabatic. Included are flow visualization results, variations of shear stress, strain rate, and viscosity, spatially-averaged heat transfer coefficients, and spatially-averaged Nusselt numbers. Overall enhanced thermal transport and convective heat transfer rates due to elastic turbulence are illustrated by the data. As such, the present investigation provides new insight 
into the effects of elastic turbulence on convective heat transfer, within an environment which has never before been employed for this purpose.

\section{Nomenclature}

A Cross area of the working fluid within the channel

c Specific heat capacity

D Perimeter where the constant temperature boundary condition is applied

h Heat transfer coefficient

k Thermal conductivity

L Characteristic length

Lc Circumferential flow passage length

$\mathrm{m} \quad$ Concentration ratio power exponent

$\mathrm{Nu} \quad$ Nusselt number for sucrose and polymer solutions

$\mathrm{Nu}_{0} \quad$ Nusselt number for Boger fluid solutions with sucrose only

$\mathrm{P} \quad$ Channel perimeter

P Static pressure

$\dot{\mathrm{q}} \quad$ Heat flux

r Radial coordinate

$\mathrm{R}_{1} \quad$ Inner radius of the flow passage

$\mathrm{R}_{2} \quad$ Outer radius of the flow passage

$\mathrm{Re}_{\mathrm{ETC}} \quad$ Elastic turbulence concentration Reynolds number

s Gap height of the viscous disk pump flow passage

t Static temperature

t' Temperature fluctuation at the outlet of flow passage

$\mathrm{t}_{\mathrm{m}} \quad$ Local mixed-mean temperature

$\mathrm{t}_{0} \quad$ Local surface temperature

$\mathrm{T} \quad$ Non-dimensional temperature

$\mathrm{T}_{\text {out }} \quad$ Mixed-mean temperature at the outlet of the flow passage

$\mathrm{T}_{\text {in }} \quad$ Mixed-mean temperature at the inlet of the flow passage

$\mathrm{T}_{\mathrm{s}} \quad$ Surface temperature

V Spatially-averaged velocity

$\mathrm{v}_{\theta} \quad$ Local circumferential component of velocity

$\mathrm{v}_{\mathrm{r}} \quad$ Local radial component of velocity

$\mathrm{v}_{\mathrm{z}} \quad$ Local normal component of velocity

z Normal coordinate 
Superscript

- Time-averaged

Greek Symbols Nomenclature

$\dot{\gamma}$ Local fluid shear rate

$\mu$ Absolute viscosity

$\rho \quad$ Fluid density

$\rho_{\mathrm{c}}$ Polyacrylamide concentration in parts per million

$\rho_{\mathrm{co}}$ Concentration constant

$\omega$ Rotational speed of the disk, $2 \pi \Omega / 60$

$\Omega$ Dimensional rotational speed of the disk, RPM

$\theta$ Circumferential coordinate

$\Delta \theta$ Circumferential span between two angular locations

\section{Viscous Disk Pump Configuration}

The viscous disk pump or VDP experimental apparatus is composed of a spinning disk and a $\mathrm{C}$-shaped channel with a fluid inlet port and a fluid outlet port, located at the two ends of the C-shaped channel. Details regarding these different items are provided by Ligrani et al. [14], and by Blanchard et al. [15]. The overall arrangement and dimensions are schematically shown in Fig. 1. The coordinate system for the flow passage is shown in Fig. 2. The flow passage height for the present investigation is $640 \mu \mathrm{m}$. Rotation speeds range from $100 \mathrm{rpm}$ to $2000 \mathrm{rpm}$. As the disk rotates, its edges create a seal to minimize the leakage of working fluid by contacting the fluid chamber wall. Rotating Couette-type flow is thus induced in the fluid chamber between the rotating disk and the stationary bottom of the channel. The work done on the fluid by the rotating disk then leads to a circumferential pressure gradient within the C-shaped channel, such that static pressure increases with streamwise development.

\section{Polyacrylamide Polymer Solutions}

Four different solutions are utilized with four different polymer concentrations: $0 \mathrm{ppm}, 80$ ppm, $100 \mathrm{ppm}$, and $150 \mathrm{ppm}$, where ppm refers to parts per million. As such, the $0 \mathrm{ppm}$ arrangement is utilized with a 65 percent sugar solution (without added polymers) to create a Newtonian Boger solution with an approximately constant viscosity that is independent of shear rate [16]. The viscoelastic solutions are then prepared by adding polyacrylamide powder into the sucrose solution. When each solution is prepared, the appropriate polymer concentration (as quantified using PAAm) is employed, along with 1 percent $\mathrm{NaCl}$, and 65 percent sucrose. The procedure for mixing the stock solution is adopted from Abed et al. [11]. 
For example, to mix a $80 \mathrm{ppm}$ solution, $0.048 \mathrm{~g}$ of PAAm (Polyacrylamide, $\mathrm{M}_{\mathrm{w}}=18,000,000$ Dalton, Polysciences Inc.) powder, $6 \mathrm{~g}$ of $\mathrm{NaCl}$, and $390 \mathrm{~g}$ sucrose are dissolved in $204 \mathrm{~g}$ DI water, as the solution is gently mixed for 4 hours in a commercial mixer with propeller at moderate speed.

\section{Viscous Disk Pump Operating and Measurement Procedures}

The disk pump is powered by an externally mounted Maxon EC32 \#118890 motor. The motor has a $48 \mathrm{~V}$ winding, a power rating of $80 \mathrm{~W}$, a maximum speed of $25,000 \mathrm{rpm}$, and a stall torque of $0.353 \mathrm{Nm}$. The motor is controlled by a Maxon ESCON 50/5 \#409510 motor controller connected to an Advanced Motion Controls model PS2X3W48 power supply. The power supply has a DC supply voltage of $48 \mathrm{~V}$, a peak current of 12 amperes, and a continuous current rating of 6 amps. The motor controller maintains a constant speed through a closed control loop and a Maxon HEDL 55 Encoder \#110514. The speed and direction of the motor are controlled by regulating voltage to the analog and digital I/O channels on the motor controller using LabVIEW 32-bit software, version 10.0.1, and a Nation Instruments USB6003 data acquisition board. The rotational speed measurement system is calibrated using a timing light. To measure the time-averaged fluid flow rate, the combination of a valve, timer, and Adam PGL2002 measuring scale is employed. The pump assembly is mounted to the base of a linear slide. The brushless motor and disk shaft are also mounted to the shuttle of the linear slide. The disk shaft is supported with two bearings, and the distal end of the disk shaft connects to the motor shaft. Elastic bands are employed to exert a constant force on the shuttle in the direction of the pump chamber to keep the disk surface flush against the bottom of the pump housing. An alignment fixture is used to mount the pump housing and pump chamber, such that the axis of the disk aligns with the center point of the pump chamber radius. The pump assembly is placed on a level surface to ensure that there are no height differences between the flow inlet and outlet ports or between the two pressure ports. After assembling the disk, disk shaft, and pump chamber, the fluid inlet and outlet tubing are press-fit into the top of the pump housing. Before the test start, the tubing, and pump housing are filled with the working fluid. Syringes are subsequently used to remove any air from the liquid which is contained within the system.

\section{Flow Visualization Apparatus and Procedures}

The apparatus employed for flow visualizations is shown in Figs. 3 and 4. The associated pump housing block is made from optically clear acrylic. Note that the flow passages turn ninety degrees toward the sides of the block, at a location which is approximately 12 to 14 $\mathrm{mm}$ beneath the surface of the channel, so that visualization views are not obstructed. The 
acrylic is polished using NOVUS plastic polish to remove any tooling marks and blemishes. An LED (light emitting diode) flashlight on a gooseneck clamp is directed at the Delrin disk to provide backlighting in the channel. A Point Gray CMLN-13S2C-CS USB camera, with a $25 \mathrm{~mm}$ lens, records images of the channel at a rate of 15 frames per second. The images are saved as 8-bit indexed .bmp image files and assembled into videos using the ffmpeg codec software. To provide contrast in the channel, Kingscote fluorescent FWT red tracer dye is injected into the channel with a New Era Pump Systems NE-1000 syringe pump at rates ranging from 0.001 to 0.065 milliliters per minute. The syringe is $28.58 \mathrm{~mm}$ in diameter and is connected through tubing to a needle positioned in the inlet flow passage. Throughout testing, the inlet reservoir is maintained at a constant level, which is aligned with the outlet tubing, to minimize variations due to hydrostatic pressure and gravity.

\section{Instantaneous and Mixed-Mean Temperature Measurement Procedures}

Within the present study, the VDP is employed for measurement of spatially-averaged heat transfer coefficients and Nusselt numbers over the entire flow passage surface area. To accomplish this task, fluid temperature is measured at the inlet and outlet of the flow passage using Omega 5TC-TT-T-40-72 fine-wire copper-constantan (Type T) thermocouples. Inlet temperature is measured using one thermocouple located at the central part of the beaker which supplies the working fluid. This temperature is representative of the mixed mean temperature at the inlet of the VDP flow passage, because of the absence of any temperature gradients within the apparatus up to and upstream of that location. In general, the inlet temperature is constant at approximately $22{ }^{\circ} \mathrm{C}$, which is the same as room temperature. The temperature of the fluid at the outlet of the VDP is measured using the apparatus which is shown in Fig. 5. The associated thermocouple at the outlet is fixed with glue and dried for 24 hours to insure that it is immobile as testing is underway. Because of the mixing which takes place within the flow, and the transient means whereby the fluid is displaced from the inlet to the outlet of the VDP flow passage, this measured temperature is representative of the fluid mixed mean temperature at the exit of the VDP flow passage.

In order to determine time-averaged magnitudes of the mean-squared temperature fluctuation, instantaneous flow temperature variations are recorded using the inlet and outlet thermocouples over a period of $90 \mathrm{~s}$ at a frequency of $100 \mathrm{~Hz}$, after reaching a steady-state VDP operating condition. The mean square of fluctuating temperature is then determined using EXCEL, relative to the time-averaged temperature. The frequency response of the thermocouple junction for these measurements is estimated to be approximately 0.12 to 0.16 milliseconds. 
As temperature data are acquired, thermocouple voltages are read sequentially using a National Instruments NI 9213 thermocouple input card mounted within a National Instruments NI cDAQ-9188 chassis connected to the computer workstation. Data are acquired at a rate of $100 \mathrm{~Hz}$, as mentioned. These terminals relay the information to a Dell Precision T1700 computer. The voltage outputs from this unit are acquired by the computer through its USB port, using LABVIEW 11.0 software. With the procedures employed, the thermocouples have a measurement accuracy of $0.05^{\circ} \mathrm{C}$ to $0.10^{\circ} \mathrm{C}$, and are calibrated in the range $20^{\circ} \mathrm{C}$ to $44^{\circ} \mathrm{C}$ using an HCTB-3020 Omega Thermo-Regulator. The overall apparatus employed to acquire these data is shown in Fig. 6.

\section{Nusselt Number Measurement and Determination}

Heat transfer measurements are based upon energy balance considerations, which utilize the mixed-mean temperature at the inlet and outlet of the viscous disk pump passage. The overall heat transfer rate is determined based upon a constant surface temperature thermal boundary condition, and upon a log-mean-temperature difference approach. The thermal boundary conditions at the side walls of the VDP passage are maintained at constant temperature, and whereas the rotating disk is adiabatic. As such, within the VDP, the bottom flow passage surface and the side walls are made of stainless aluminum $(\mathrm{k}=205 \mathrm{~W} / \mathrm{mK})$. The rotating disk is machined from PEEK plastic with a thermal conductivity of $0.252 \mathrm{~W} /(\mathrm{m} \cdot \mathrm{K})$, to minimize heat loss from the flow passage, and to minimize shape variations which may occur as heat transfer tests are underway.

With these considerations in mind, the bottom and side walls of VDP flow passage are maintained at constant temperature, $\mathrm{T}_{\mathrm{s}}$, and the disk which is adjacent to the working fluid is adiabatic, such that $\dot{q}$ for the disk surface is zero. The log-mean-temperature difference equation is then applied between the outlet and the inlet of the VDP flow passage, as follows

$$
\ln \left(\frac{T_{\text {out }}-T_{s}}{T_{\text {in }}-T_{S}}\right)=-\frac{D L}{\rho c \mathrm{VA}} h
$$

Here, $\mathrm{L}$ is the characteristic length which is given by

$$
L=\frac{\pi\left(R_{2}+R_{1}\right)}{2}
$$


$\mathrm{P}$ is then the channel perimeter, and $\mathrm{D}$ is the portion of the perimeter where the constant temperature boundary condition is applied. These quantities are determined from the equations given by

$$
P=2\left(R_{2}-R_{1}\right)+2 s \quad D=\left(R_{2}-R_{1}\right)+2 s
$$

The total heat flux into the VDP flow passage is then expressed using

$$
\dot{q}=\left(T_{\text {out }}-T_{\text {in }}\right) \rho c \mathrm{VA}
$$

where $T_{\text {in }}$ and $T_{\text {out }}$ are inlet and outlet flow passage mixed mean temperatures. Combining Eqns. (1) and (4) then gives

$$
\dot{q}=h L D \frac{T_{\text {out }}-T_{\text {in }}}{\ln \left(\frac{T_{\text {out }}-T_{s}}{T_{\text {in }}-T_{s}}\right)}
$$

After rearrangement, the overall VDP passage heat transfer coefficient is then determined using

$$
h=\frac{\dot{q}}{L D \frac{T_{\text {out }}-T_{\text {in }}}{\ln \left(\frac{T_{\text {out }}-T_{S}}{T_{\text {in }}-T_{S}}\right)}}
$$

The overall Nusselt number is subsequently given by

$$
N u=\frac{h s}{k}
$$

where $h$ is the overall flow passage heat transfer coefficient.

\section{Experimental Results}

Presented are results which illustrate transition from laminar flow to elastic turbulence flow, along with the associated variations of surface convective heat transfer. Included are flow visualization results, heat transfer coefficient values, Nusselt numbers, and timeaveraged magnitudes of the mean square of instantaneous temperature fluctuation. Viscous disk pump rotation speeds of $500 \mathrm{rpm}, 1000 \mathrm{rpm}, 1500 \mathrm{rpm}$ and $2000 \mathrm{rpm}$ are utilized. Associated molecular fluid properties are determined from Abed et al. [11] and are given in Table 2. For most conditions of the present study (with the exception of viscosity), property values for $80 \mathrm{ppm}, 100 \mathrm{ppm}$, and $150 \mathrm{ppm}$ polyacrylamide solutions with 65 percent sucrose, are within a few percent of values for the 65 percent sucrose solution by itself. 


\subsection{Flow visualization results}

Flow visualization images for the pure sucrose solution, and for the $100 \mathrm{ppm}$ polymer/sucrose solution are presented in Fig. 7 for a viscous disk pump flow passage height of $640 \mu \mathrm{m}$. Visualization images in Fig. 7a are given for the pure sucrose solution for rotational speeds of 100 RPM, 500 RPM, 1000 RPM, and 1800 RPM, which correspond to overall shear rates of $29.21 \mathrm{1} / \mathrm{s}, 146.051 / \mathrm{s}, 292.1 \mathrm{1} / \mathrm{s}$, and $525.78 \mathrm{1} / \mathrm{s}$, respectively. Visualization images in Fig. $7 \mathrm{~b}$ are shown for the $100 \mathrm{ppm}$ viscoelastic/sucrose solution at the same magnitudes of rotation speed and shear rate. These data are obtained using the flow visualization apparatus and procedures which are described above, wherein dye is injected near the middle of the inlet flow passage.

Dye path lines in Fig. 7a, for the Newtonian Boger fluid, are smooth, narrow, and generally well defined with little distortion, as the rotation speed and overall shear rate change. Here, dye trajectories follow laminar flow streamlines. As a result, only minimal secondary flows are present, with very little augmented mixing present within the channel.

However, dramatically different behavior is present for the $100 \mathrm{ppm}$ polyacrylamide / 65 percent sucrose solution flow in Fig. 7b. Here, dye trajectories and increased mixing of dye distributions illustrate mixing and agitation due to the elastic turbulence. The mixing is significantly enhanced, as evidenced by dye spreading in the radial direction, immediately downstream of the inlet of the flow passage. The dye is spread throughout the entire flow passage, over the entire radial extent of the flow passage. Such behavior is associated with enhanced local flow strain, associated with local flow turning and flow curvature. Such strain leads to initial polymer distortion and agitation, and increased polymer stretching in the circumferential direction. As such, the resulting dye spreading for shear rates as low as 29.21 $1 / \mathrm{s}$, are associated with the transition onset and development of the elastic turbulence.

The differences in flow visualization images between Figs. $7 \mathrm{a}$ and $7 \mathrm{~b}$ are not due to increased viscosity values alone, because the natural tendency of increased viscosity (with no polymers present) associated with the Newtonian, Boger fluid is suppression of flow fluctuations. In addition, centrifugal instabilities associated with streamline curvature are not responsible for the observed variations, because associated Dean numbers are not large enough to allow development of the associated centrifugal-instability induced secondary flows. The experimental conditions associated with transition also cannot be characterized by one Dean number, and associated Dean numbers do not vary with polymer concentration. Within the present investigation, Reynolds numbers, based upon flow passage gap height and spatially-averaged velocity, range from 0.03 to 0.24 . Reynolds numbers, based upon flow 
passage gap height and rotation speed at the flow passage centerline, range from 0.11 to 0.87 . Because the radius of the convex surface is the same as the radial extent of the flow channel, associated Dean numbers cover the same range of values.

\subsection{Viscosity variation with shear rate and shear stress variation with shear rate}

Figure 8 shows the variations of viscosity with shear rate for two different polyacrylamide solutions, as well as for the Newtonian Boger sucrose solution, for overall shear rates from 0 1/s to about 400 1/s. These data are obtained using the Anton Paar Rheometer with a fluid temperature of $20^{\circ} \mathrm{C}$. Within Fig. 8, viscosity for the Boger solution is constant as shear rate ranges from 0 to about 400 1/s. For both polyacrylamide solutions of $80 \mathrm{ppm}$ and $100 \mathrm{ppm}$, Fig. 8 shows that viscosity first decreases with increasing shear rate. As shear rate then increases further, viscosity then increases with increasing shear rate. The condition where this change occurs is associated with the onset of transition to elastic turbulence. The stretch and twist of the polymer within the solution produces an effect on the mixing and transport of the solution prior to the development of elastic turbulence. Once the elastic turbulence is triggered, polymer agitation and coil stretch is occurring, which leads to the change of the viscosity slope. The shear rate where the distinctive change in data slope occurs is consistent with flow visualization results.

\subsection{Energy analysis for the viscous disk pump}

The energy equation is developed for the flow passage shown in Fig. 2, from the inlet to the exit of the VDP over an angular arc of 180 degrees. For this analysis, the flow is assumed to be incompressible, steady, Newtonian, and laminar, with constant density and constant thermal properties. No additional source terms are employed. The resulting constant property energy equation includes advection and molecular diffusion in circumferential, radial, and normal directions, as given by

$$
\rho c\left(v_{r} \frac{\partial t}{\partial r}+\frac{v_{\theta}}{r} \frac{\partial t}{\partial \theta}+v_{z} \frac{\partial t}{\partial z}\right)=k\left(\frac{1}{r} \frac{\partial}{\partial r}\left(r \frac{\partial t}{\partial r}\right)+\frac{1}{r^{2}} \frac{\partial^{2} t}{\partial \theta^{2}}+\frac{\partial^{2} t}{\partial z^{2}}\right)
$$

Diffusion in the normal direction is more significant than in the circumferential direction because the flow passage height $\mathrm{h}$ is relatively small. In addition, the flow is fully developed with respect to circumferential development. As a result, circumferential velocity does not change in a significant manner as the flow advects through the VDP flow passage. Because of this flow arrangement wherein flow passage height $h$ is small and $h /\left(R_{2}-R_{1}\right)<<1$, velocity components in the $\mathrm{z}$ and $\mathrm{r}$ directions are then either very small or zero, and are therefore neglected. The resulting simplified energy equation is then expressed as follows 


$$
k\left(\frac{1}{r} \frac{\partial}{\partial r}\left(r \frac{\partial t}{\partial r}\right)+\frac{\partial^{2} t}{\partial z^{2}}\right)=\rho c\left(\frac{v_{\theta}}{r} \frac{\partial t}{\partial \theta}\right)
$$

Equation (10) thus accounts for molecular diffusion of static temperature in the radial and normal directions, and advection of static temperature in the circumferential direction.

According to Ligrani et al. [14] and Blanchard et al. [15], the corresponding circumferential momentum equation contains a pressure gradient term, and terms to account to diffusion of circumferential momentum in the $\mathrm{z}$ direction and in the $\mathrm{r}$ direction.

$$
\frac{1}{r} \frac{\partial P}{\partial \theta}=\mu\left[\frac{\partial}{\partial r}\left(\frac{1}{r} \frac{\partial\left(r v_{\theta}\right)}{\partial r}\right)+\frac{\partial^{2} v_{\theta}}{\partial z^{2}}\right]
$$

Associated velocity boundary conditions are then given by

$$
\begin{gathered}
v_{\theta}(r, 0)=0 \\
v_{\theta}(r, s)=r \omega
\end{gathered}
$$

The resulting velocity profile is then of the form

$$
v_{\theta}=\frac{s^{2}}{2 \mu} \frac{1}{r} \frac{\Delta P}{\Delta \theta}\left[\left(\frac{Z}{S}\right)^{2}-\frac{Z}{s}\right]+r \omega \frac{Z}{S}
$$

Again considering Eqn. (10), this equation is now re-arranged by employing a nondimensional temperature, which is given by the following equation

$$
T=\frac{t_{0}-t}{t_{0}-t_{m}}
$$

Here, $t_{m}$ is the mixed-mean temperature and $t_{0}$ is the wall temperature. In addition, $\left(t_{0}-t_{m}\right)$ is constant in the radial and vertical directions. Note that the wall temperature is also invariant in the radial direction. Within the present investigation, the side walls of the channel are maintained at constant temperature and the disk touching the working fluid provides an insulated zero heat flux boundary condition. Because the boundary condition for the bottom surface of the flow passage is constant surface temperature, the bottom surface temperature is independent of circumferential direction, which is expressed using

$$
\frac{\partial t_{0}}{\partial \theta}=\frac{d t_{0}}{d \theta}=0
$$

Consequently 


$$
\frac{\partial t}{\partial \theta}=\left(\frac{t_{0}-t}{t_{0}-t_{m}}\right)\left(\frac{d t_{m}}{\partial \theta}\right)-\left(t_{0}-t_{m}\right) \frac{\partial T}{\partial \theta}
$$

The resulting energy equation in non-dimensional form is then given by

$$
k\left(\frac{\partial^{2} T}{\partial r^{2}}+\frac{1}{r} \frac{\partial T}{\partial r}+\frac{\partial^{2} T}{\partial z^{2}}\right)=-\rho c\left(\frac{v_{\theta}}{r}\right)\left\{\left(\frac{t_{0}-t}{t_{0}-t_{m}}\right)\left(\frac{1}{t_{0}-t_{m}}\right)\left(\frac{d t_{m}}{\partial \theta}\right)-\frac{\partial T}{\partial \theta}\right\}
$$

The mixed-mean temperature, $\mathrm{t}_{\mathrm{m}}$, varies in the circumferential direction, and as a result, $\frac{d t_{m}}{d \theta}$ is not neglected. Because of the complexity of Eqn. (17), it cannot be solved analytically.

As mentioned, Eqn. (17) represents incompressible, steady, Newtonian, and laminar flow, with constant density and constant thermal properties within the VDP flow passage. If elastic turbulence is present, the equation would also include advection in all three directions: circumferential, radial, and normal.

\subsection{Heat transfer due to elastic turbulence}

Convective heat transfer characters for polyacrylamide solution flows are now presented. Included are variations of heat transfer coefficient and Nusselt number with polymer concentration (Figs. 9 an 10), with time-averaged magnitude of the mean-square of temperature fluctuations (Fig. 11), and with a modified Reynolds number employed to characterize the onset and development of elastic turbulence (Fig. 12). Experimental data are obtained for rotational speeds of $500 \mathrm{rpm}, 1000 \mathrm{rpm}, 1500 \mathrm{rpm}$ and $2000 \mathrm{rpm}$, which correspond to overall shear rates of $146.051 / \mathrm{s}, 292.11 / \mathrm{s}, 438.151 / \mathrm{s}$, and $584.21 / \mathrm{s}$, respectively.

Figure 9 shows that the value of the heat transfer coefficient increases by important amounts as polymer concentration becomes larger for all four shear rates. For a constant value of polymer concentration, heat transfer coefficients also increase as shear rate increases. Heat transfer coefficients for all four shear rates are also included for Newtonian Boger fluids for a polymer concentration value $\rho$ of $0 \mathrm{ppm}$. Associated Nusselt number data in Fig. 10 show consistent trends. In both figures, values with polyacrylamide added to the flow are always higher, relative to Boger fluid values, as a result of the presence of elastic turbulence. The resulting coil stretch transition is induced by flow strain from streamline curvature, as the flow turns into the entrance of the VDP and then advects through the curved VDP passage. Such variations from the onset and development of elastic turbulence are consistent with viscosity variations in Fig. 8, and with flow visualization results in Fig. 7. 
Presented in Fig. 11 are variations of the ratio of Nusselt number with elastic turbulence, relative to the Nusselt number for a Newtonian Boger fluid at the same shear rate. This ratio is presented as it varies with time-averaged magnitude of the mean-squared temperature fluctuation, $\bar{t}^{\prime 2}$, measured at the outlet of the VDP flow passage. Note that the addition of the polyacrylamide, and the resulting flow mixing and chaotic motions, boosts unsteadiness, as quantified by increased scalar temperature fluctuations within the flow passage. No similar increase in temperature fluctuation magnitude is observed for Boger Newtonian solution flows at equivalent shear rates. The important conclusion from Fig. 11 is the strong correlation between Nusselt number ratio and $\bar{t}^{2}$ magnitudes, regardless of overall flow shear rate magnitude. Such correlation is illustrated by the collection of data sets for shear rates of $146.051 / \mathrm{s}, 292.11 / \mathrm{s}, 438.21 / \mathrm{s}$, and $584.21 / \mathrm{s}$ into a continuously increasing distribution. Such unsteady temperature fluctuation behavior provides additional evidence of local flow chaotic motions resulting from polymer interactions and intertwining between polymers, which are associated with elastic turbulence.

According to Abed et al. [11], surface convective heat transfer is enhanced by elastic turbulence generated by the non-linear interactions between elastic normal stresses created within the flowing high-molecular-weight polymer solution and the streamline curvature of a serpentine channel. According to this investigation, the resulting viscoelastic turbulence increases surface heat transfer for a $100 \mathrm{ppm}$ polymer solution (with 65 percent sucrose) by as much as 240 percent, and by as much as 380 percent for a $500 \mathrm{ppm}$ polymer solution (also with 65 percent sucrose). Results from the present study are approximately consistent, since elastic turbulence generated by the polymer presence enhances the heat transfer up to approximately 240 percent for a $100 \mathrm{ppm}$ polymer solution (also with 65 percent sucrose).

A new parameter, the modified Reynold number, $\mathrm{Re}_{\mathrm{ETC}}$, is introduced to characterize the onset and development of elastic turbulence within the viscous disk pump. This new parameter is given by

$$
\operatorname{Re}_{E T C}=\dot{\gamma} \frac{\rho}{\mu} L_{c}^{2}\left(\frac{\rho_{c}}{\rho_{c 0}}\right)^{m}
$$

This modified Reynolds number includes dependence upon shear rate, streamwise development length scale, flow static density, absolute viscosity, and polymer concentration, all of which have significant dependence upon transition and development of elastic turbulence. Values employed for $\mathrm{m}$ and $\rho_{\mathrm{co}}$ are 1.747 and $550 \mathrm{ppm}$, respectively. Within this 
parameter, shear rate is included because of its connection to stretching of the polymer molecules. The additional length scale within the shear rate is countered by squaring the circumferential channel length scale of the flow, $\mathrm{L}_{\mathrm{C}}$. This modified Reynold number is presented in Fig. 12 as it varies with Nusselt number ratio. In general, Fig. 12 shows that $\mathrm{Re}_{\mathrm{ETC}}$ increases with Nusselt number ratio, with somewhat different dependence for the different shear rates of $146.051 / \mathrm{s}, 292.1$ 1/s, $438.151 / \mathrm{s}$, and 584.2 1/s.

\section{Summary and Conclusions}

Elastic turbulence is employed within the present investigation to enhance convective heat transfer at very small scales and at very low Reynolds numbers. A miniature viscous disk pump or VDP is utilized to investigate flow and heat transfer, where the latter are based upon energy balance measurements which utilize the mixed-mean temperature at the inlet and outlet of the viscous disk pump passage. The overall heat transfer rate is determined based upon a constant surface temperature thermal boundary condition, and upon a log-meantemperature difference approach. The VDP operates at rotation speeds of 500 RPM, 1000 RPM, 1500 RPM, 1800 RPM, and 2000 RPM, which produce overall shear rates across the flow cross section of $146.051 / \mathrm{s}, 292.11 / \mathrm{s}, 438.151 / \mathrm{s}, 525.781 / \mathrm{s}$, and $584.21 / \mathrm{s}$. A channel depth of $640 \mu \mathrm{m}$ is employed. Elastic turbulence is induced by adding polyacrylamide to water solutions with 65 percent sucrose by mass. Significant enhancements of mixing and transport are observed, which are associated with the onset and development of elastic turbulence. Such behavior is verified, relative to an increased viscosity Boger fluid, using flow visualization results, rheometer viscosity variations with shear rate, and increases of overall magnitudes of convective heat transfer coefficient and Nusselt number, which are augmented by as much as 240 percent.

Note that these enhancements are not due to increased viscosity values alone, because the natural tendency of increased viscosity (with no polymers present) associated with the Newtonian, Boger fluid is suppression of flow fluctuations. In addition, centrifugal instabilities associated with streamline curvature are not responsible for the observed variations, because associated Dean numbers are not large enough to allow development of the associated centrifugal-instability induced secondary flows. In addition, the experimental conditions associated with elastic turbulence transition cannot be characterized by one Dean number, and associated centrifugal instabilities (and associated Dean numbers) do not vary with polymer concentration.

Consequently, a new modified Reynold number, $\mathrm{Re}_{\mathrm{ETC}}$, is introduced to characterize the onset and development of elastic turbulence within the viscous disk pump. This modified 
Reynolds number includes dependence upon shear rate, streamwise development length scale, flow static density, absolute viscosity, and polymer concentration, all of which have significant dependence upon transition and development of elastic turbulence. This modified Reynold number increases with Nusselt number ratio, with someone different dependence for the four different shear rates which are considered. Both the Nusselt number and the heat transfer coefficient increase by important amounts as polymer concentration becomes larger for all four shear rates. For a constant value of polymer concentration, heat transfer coefficients and Nusselt numbers also increase as shear rate increases. Values with polyacrylamide added to the flow are always higher, relative to Boger fluid values, as a result of the presence of elastic turbulence. Such variations from the onset and development of elastic turbulence are consistent with viscosity variations with shear rate, and with flow visualization results. Within the present study, elastic turbulence generated by the polymer presence enhances the heat transfer up to approximately 240 percent for a $150 \mathrm{ppm}$ polymer solution (with 65 percent sucrose). In addition, Nusselt number ratio is strongly correlated with $\bar{t}^{2}$ magnitudes, regardless of overall flow shear rate magnitude, for shear rates of 146.0 1/s, $292.11 / \mathrm{s}, 438.21 / \mathrm{s}$, and $584.21 / \mathrm{s}$. Such unsteady temperature fluctuation behavior provides additional evidence of local flow chaotic motions resulting from intense polymer interactions and intertwining.

\section{Acknowledgements}

The research described in this paper is supported by the U.S. National Science Foundation, Grant No. CBET-1501587. The Anton Paar Corporation is acknowledged for loaning a commercial Anton Paar Rheometer MCR 302 to the University of Alabama in Huntsville for use during a portion of the present investigation. Mr. Benjamin Lund is also acknowledged for his efforts in regard to acquisition and analysis of related experimental data. 


\section{References}

[1] Groisman A., Steinberg V, Elastic turbulence in curvilinear flows of polymer solutions, New Journal of Physics 6 (29) ( 2004) 29-48.

[2] Naschie M. S. E., Athel S. A., Kapitaniak T, A note on elastic turbulence and diffusion. Journal of Sound and Vibration 155 (3) (1992) 515-522.

[3] Berti S., Boffetta G, Elastic waves and transition to elastic turbulence in a twodimensional viscoelastic Kolmogorov flow, Physical Review E 82 (2010) (036314) 1-8.

[4] Berti S., Bistagnino A., Boffetta G., Celani A., Musacchio S, Two-dimensional elastic turbulence, Physical Review E 77 (2008) (055306) 1-4.

[5] Schiamberg B. A., Shereda L. T., Hu H., Larson R. G, Transitional pathway to elastic turbulence in torsional, parallel-plate flow of a polymer solution, Journal of Fluid Mechanics 554 (2006) 191-216.

[6] Li F.-C., Kinoshita H., Li X.-B., Oishi M., Fujii T., Oshima M, Creation of very-lowReynolds-number chaotic fluid motions in microchannels using viscoelastic surfactant solution, Experimental Thermal and Fluid Science 34 (200) 20-27.

[7] Hartnett,J.P., Kostic, M, Heat transfer to a viscoelastic fluid in laminar flow through a rectangular channel, International Journal of Heat and Mass Transfer 28 (1985) 1147-1155.

[8] Hartnett,J.P, Viscoelastic fluids: a new challenge in heat transfer, Journal of Heat Transfer 14 (1992) 296-303.

[9] Zhang H.N., Kunugi T., Li F.C., Yu B, DNS study of the elastic turbulence in a 3D parallel plate channel, $14^{\text {th }}$ European Turbulence Conference, ENS Lyon, France, 2013, September 1-4.

[10] Zhang H.N., Li F.C., Cao Y., Kunugi T., Yu B, Direct numerical simulation of elastic turbulence and its mixing-enhancement effect in a straight channel, Chinese Physics B 22(2) (2013) 024703.

[11] Abed W., Whalley R., Dennis D.J.C., Poole R.J, Experimental investigation of the impact of Elastic turbulence on heat transfer in a serpentine channel, Journal of NonNewtonian Fluid Mechanics 231(2016)68-78.

[12] Whalley R., Abed W., Dennis D.J.C., Poole R.J, Enhancing heat transfer at the microscale using elastic turbulence, Theoretical and Applied Mechanics Letters 5 (2015) 103-106.

[13] Traore B., Castelain C., Burghelea T, Efficient heat transfer in a regime of elastic turbulence, Journal of Non-Newtonian Fluid Mechanics 223 (2015) 62-76.

[14] Ligrani P. M., Jiang H., Lund B., Jin J. S, Deviations due to non-Newtonian influences within a miniature viscous disk pump, ASME Transactions-Journal of Fluids Engineering, 135 (3) (2013) (031205) 1-12.

[15] Blanchard, D., Ligrani, P. M., Gale, B, Miniature Single-Disk Viscous Pump (SingleDVP), Performance Characterization, ASME Transactions - Journal of Fluids Engineering, 128 (2006) 602-610.

[16] James D.F, Boger fluids, Annual Review of Fluid Mechanics, 41 (2009) 129-142. 
Table 1. Uncertainty values of experimentally measured quantities.

\begin{tabular}{|lcc|}
\hline Polymer concentration & Temperature & Nussult number \\
& & \\
$\mathbf{0}$ (sucrose solution) & $8.34 \%$ & $9.18 \%$ \\
$\mathbf{8 0}$ & $6.53 \%$ & $7.78 \%$ \\
$\mathbf{1 0 0}$ & $5.27 \%$ & $6.28 \%$ \\
$\mathbf{1 5 0}$ & $4.91 \%$ & $5.04 \%$ \\
\hline
\end{tabular}


Table 2. Thermal properties of working fluids, where viscosity, density, specific heat, and thermal conductivity are from Abed et al. [11].

\begin{tabular}{|c|c|c|c|c|c|c|c|c|c|}
\hline $\begin{array}{c}\text { Rotation } \\
\text { speed }\end{array}$ & Concentration & $\begin{array}{c}\text { Nussult } \\
\text { number }\end{array}$ & $\begin{array}{c}\text { Shear } \\
\text { rate }\end{array}$ & $\begin{array}{c}\text { Flow } \\
\text { rate }\end{array}$ & Density & Viscosity & $\begin{array}{c}\text { Specific } \\
\text { heat }\end{array}$ & $\begin{array}{c}\text { Thermal } \\
\text { conductivity }\end{array}$ & Re $_{\text {ETC }}$ \\
\hline $\mathrm{rpm}$ & $\mathrm{ppm}$ & & $1 / \mathrm{s}$ & $\mathrm{g} / \mathrm{s}$ & $\mathrm{kg} / \mathrm{m}^{3}$ & $\mathrm{~Pa} \cdot \mathrm{s}$ & {$[\mathrm{J} / \mathrm{Kg} \mathrm{K}]$} & {$[\mathrm{W} / \mathrm{mK}]$} & \\
\hline 500 & 0 & 3.9 & 146.0 & 0.035 & 1311 & 0.179 & 2606 & 0.368 & 33.7 \\
\hline 500 & 80 & 4.4 & 146.0 & 0.034 & 1315 & 0.200 & 2561 & 0.368 & 483.1 \\
\hline 500 & 100 & 4.6 & 146.0 & 0.027 & 1315 & 0.237 & 2542 & 0.368 & 636.5 \\
\hline 500 & 150 & 6.7 & 146.0 & 0.020 & 1316 & 0.356 & 2600 & 0.368 & 954.7 \\
\hline 1000 & 0 & 5.0 & 292.1 & 0.040 & 1311 & 0.179 & 2606 & 0.368 & 67.5 \\
\hline 1000 & 80 & 6.3 & 292.1 & 0.035 & 1315 & 0.243 & 2561 & 0.368 & 795.2 \\
\hline 1000 & 100 & 6.4 & 292.1 & 0.033 & 1315 & 0.288 & 2542 & 0.368 & 1047.7 \\
\hline 1000 & 150 & 8.3 & 292.1 & 0.023 & 1316 & 0.432 & 2600 & 0.368 & 1571.5 \\
\hline 2000 & 0 & 5.4 & 584.1 & 0.047 & 1311 & 0.180 & 2606 & 0.368 & 134.2 \\
\hline 2000 & 80 & 10.2 & 584.1 & 0.028 & 1315 & 0.231 & 2561 & 0.368 & 1673.1 \\
\hline 2000 & 100 & 13.6 & 584.1 & 0.025 & 1315 & 0.274 & 2542 & 0.368 & 2204.0 \\
\hline 2000 & 150 & 18.4 & 584.1 & 0.026 & 1316 & 0.411 & 2600 & 0.368 & 3306.0 \\
\hline
\end{tabular}




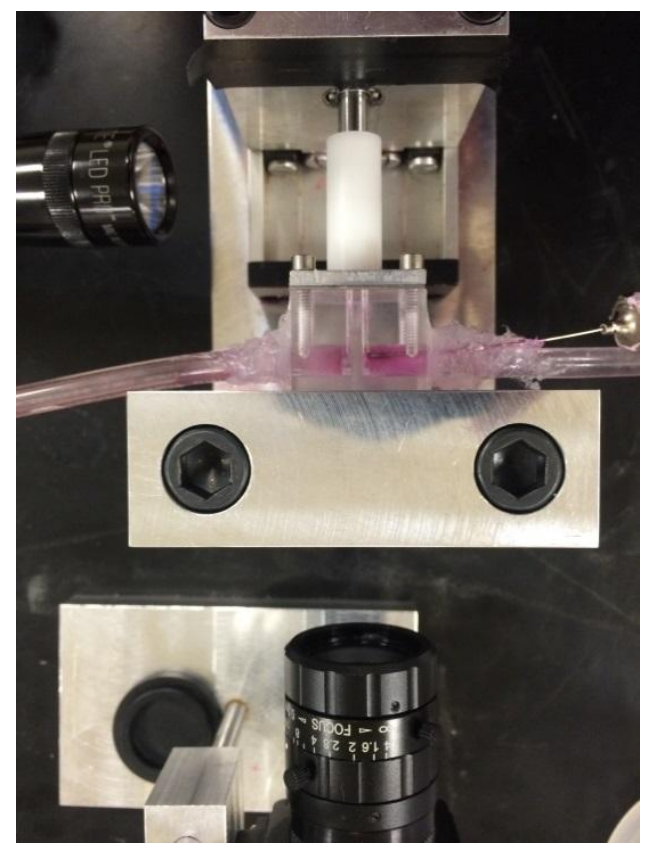

(a)

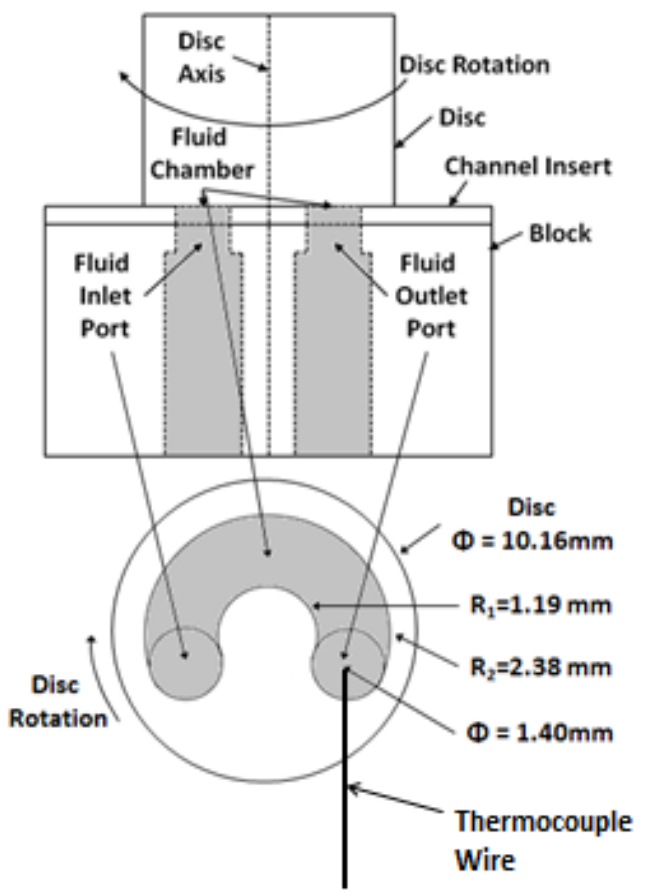

(b)

Figure 1. (a) Photograph of apparatus, showing disc and block, as well as camera and light source used for visualizations. (b) Cross-sectional and side views of the viscous disk pump. The shaded portion indicates the fluid flow path. The black line indicates the location of the thermocouple. All dimensions are given in millimeters. 


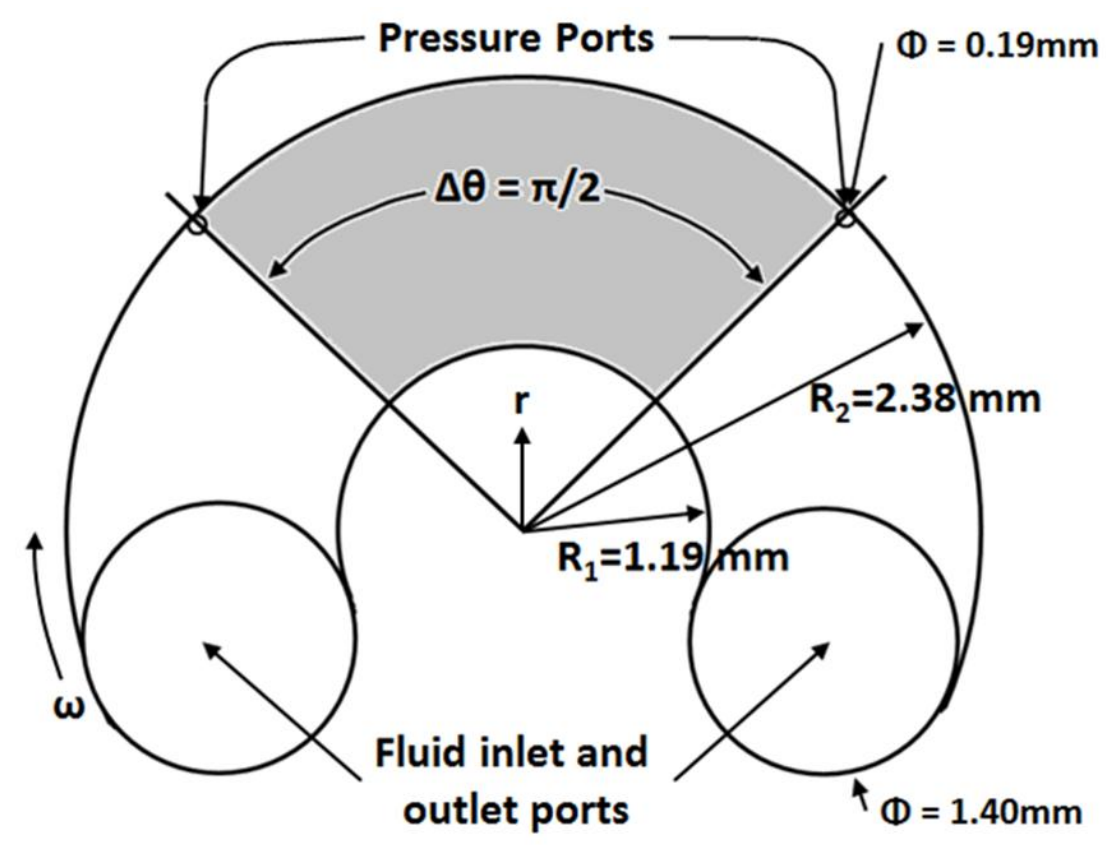

Figure 2. Configuration of the viscous disk pump, including coordinate system. The shaded region of the pump chamber is used for the flow analysis. The $z$ coordinate is directed normal to the surface, and measured from the stationary flat bottom surface of the flow passage. 


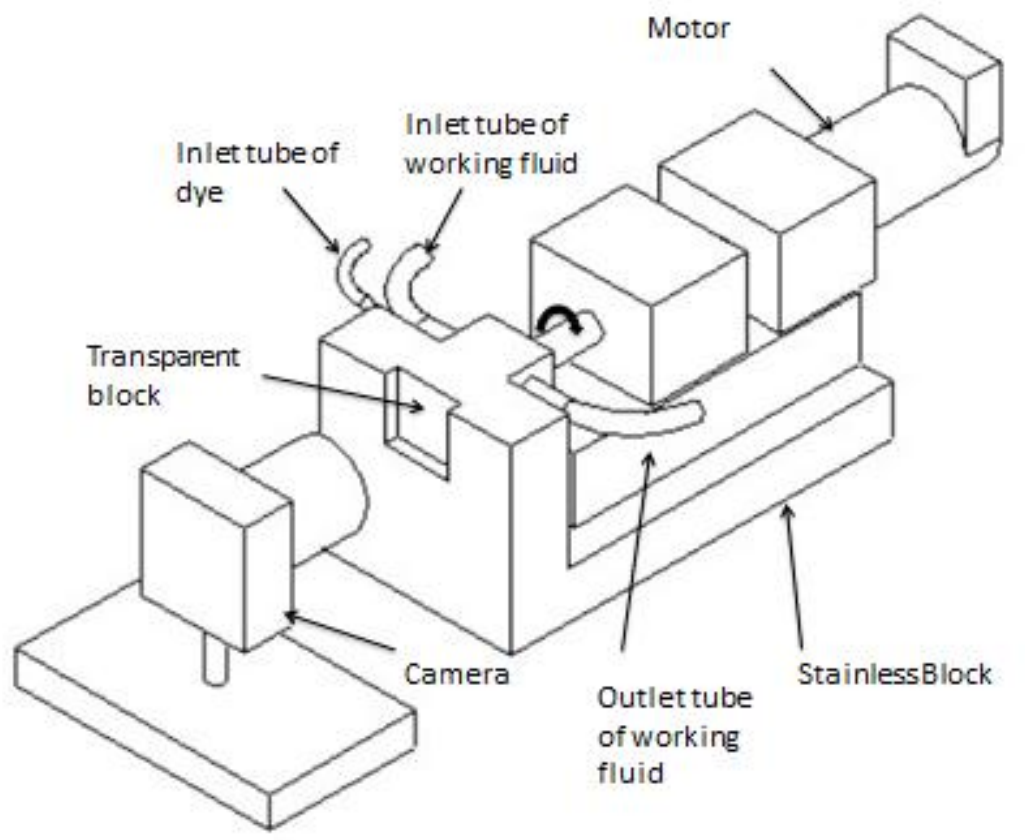

(a)

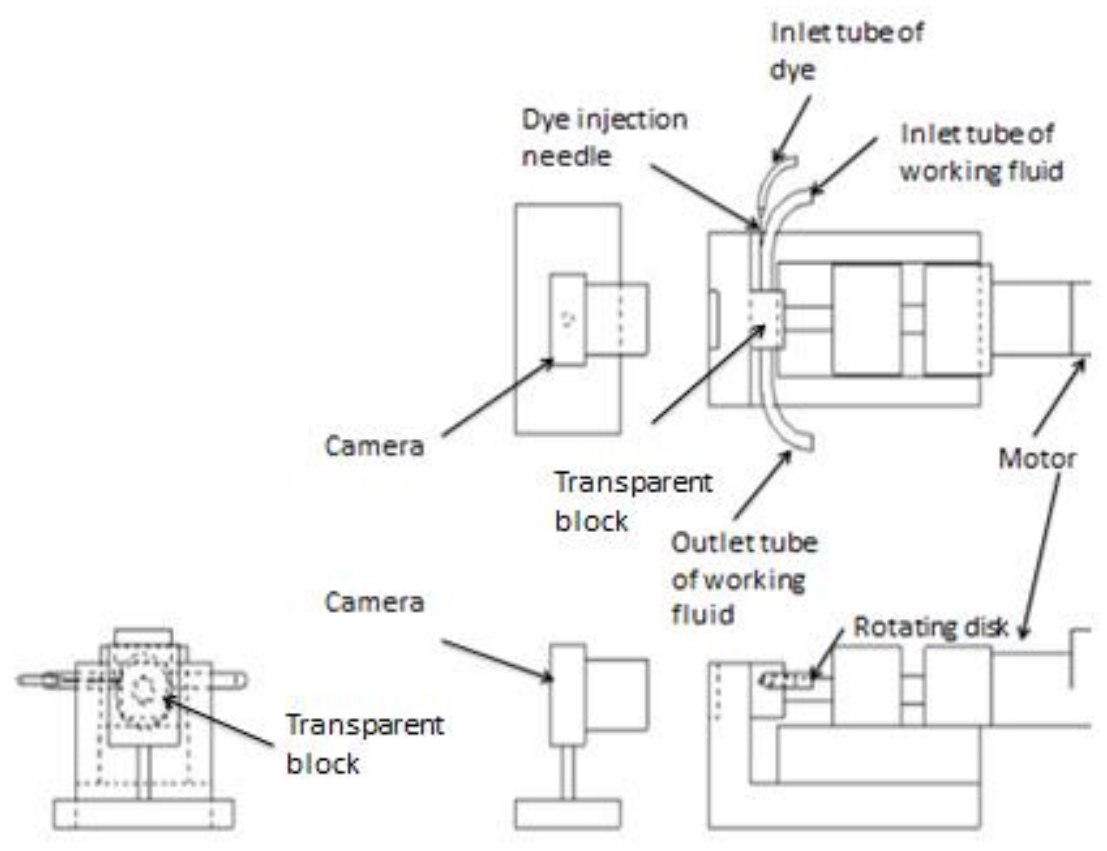

(b)

Figure 3. (a) Three-dimensional view of the flow visualization device with the dye injection. (b) Front view, side view and top view of the flow visualization device. 


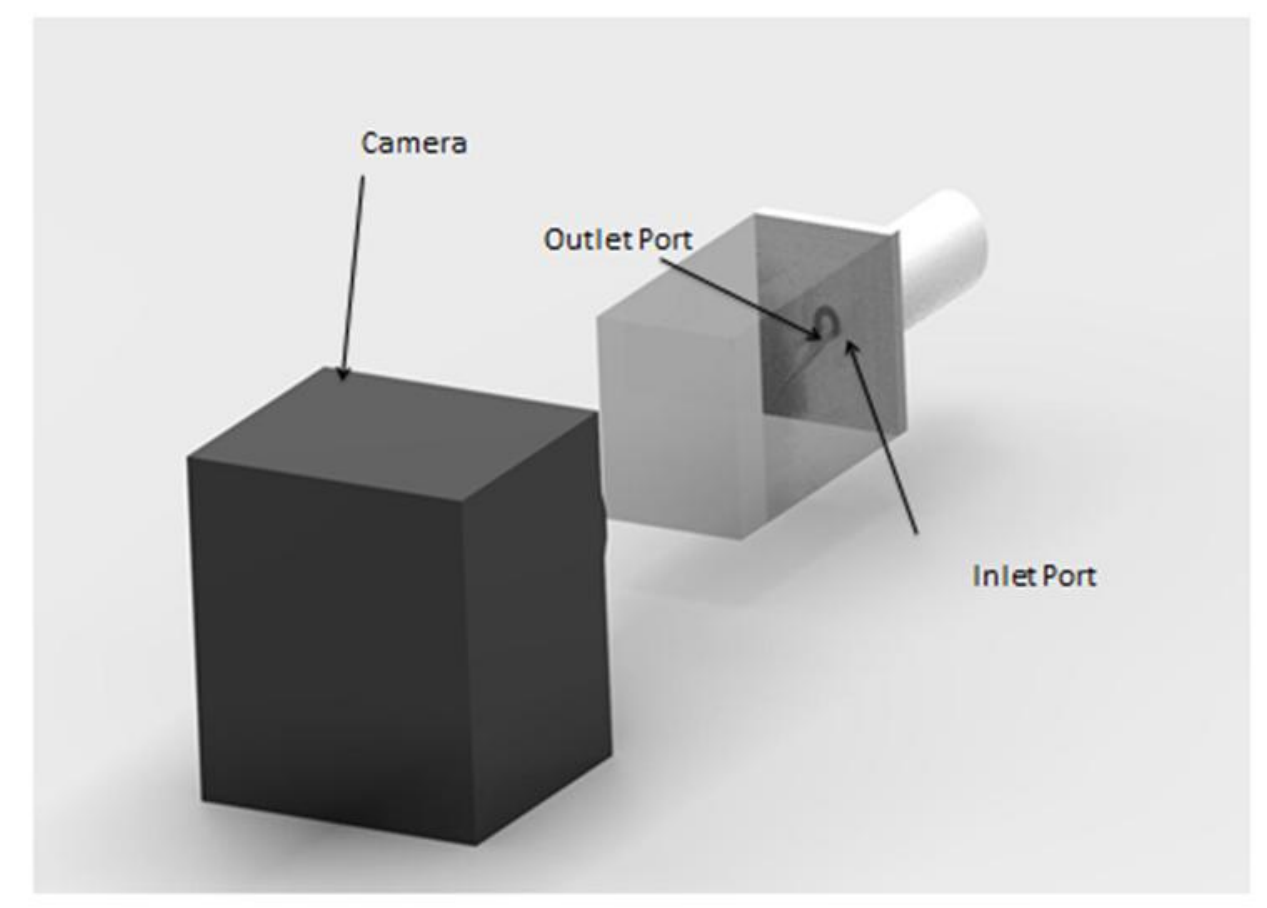

Figure 4. Transparent block arrangement and location relative to flow visualization camera. 


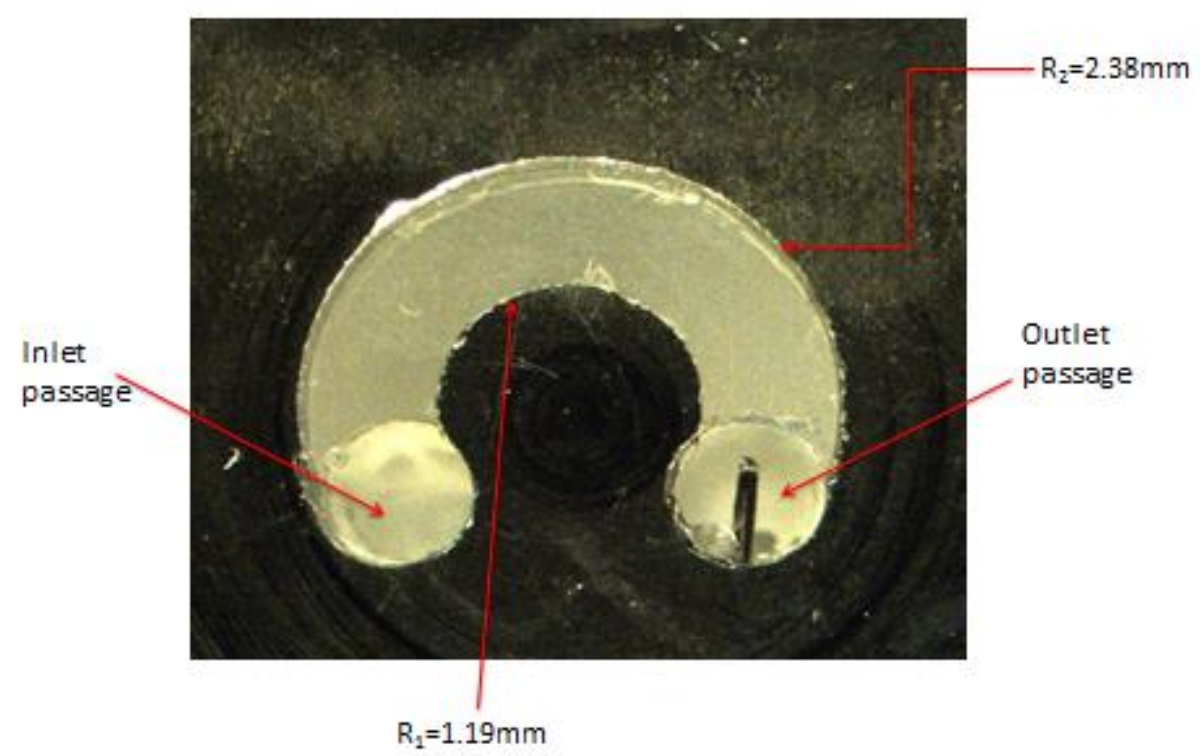

(a)

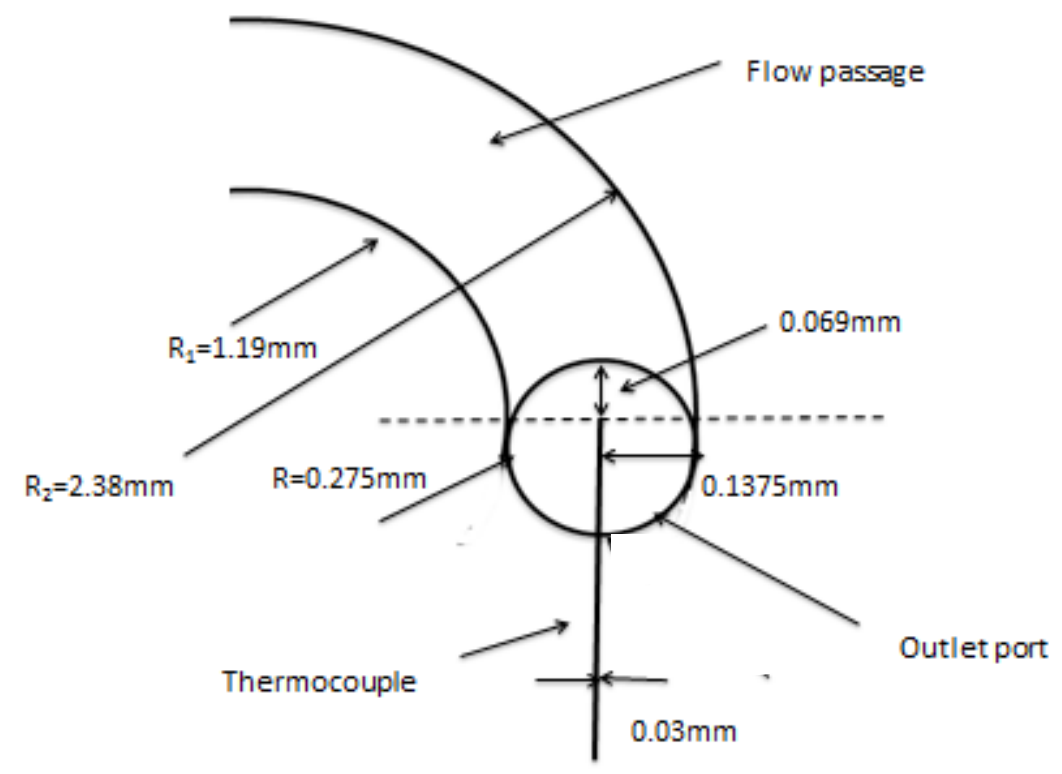

(b)

Figure 5. (a) Photograph of the location of the thermocouple junction at the flow passage outlet. (b) Dimensions of the thermocouple junction for the flow passage outlet. 


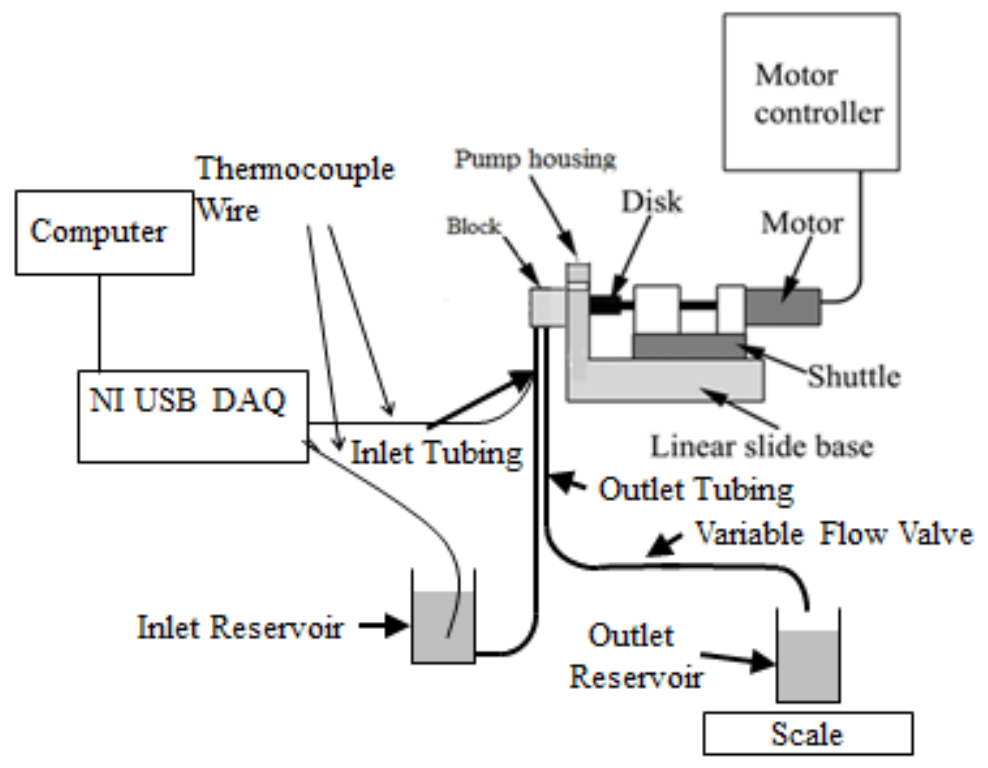

Figure 6. Arrangement of the viscous disk pump heat transfer measurement apparatus. 

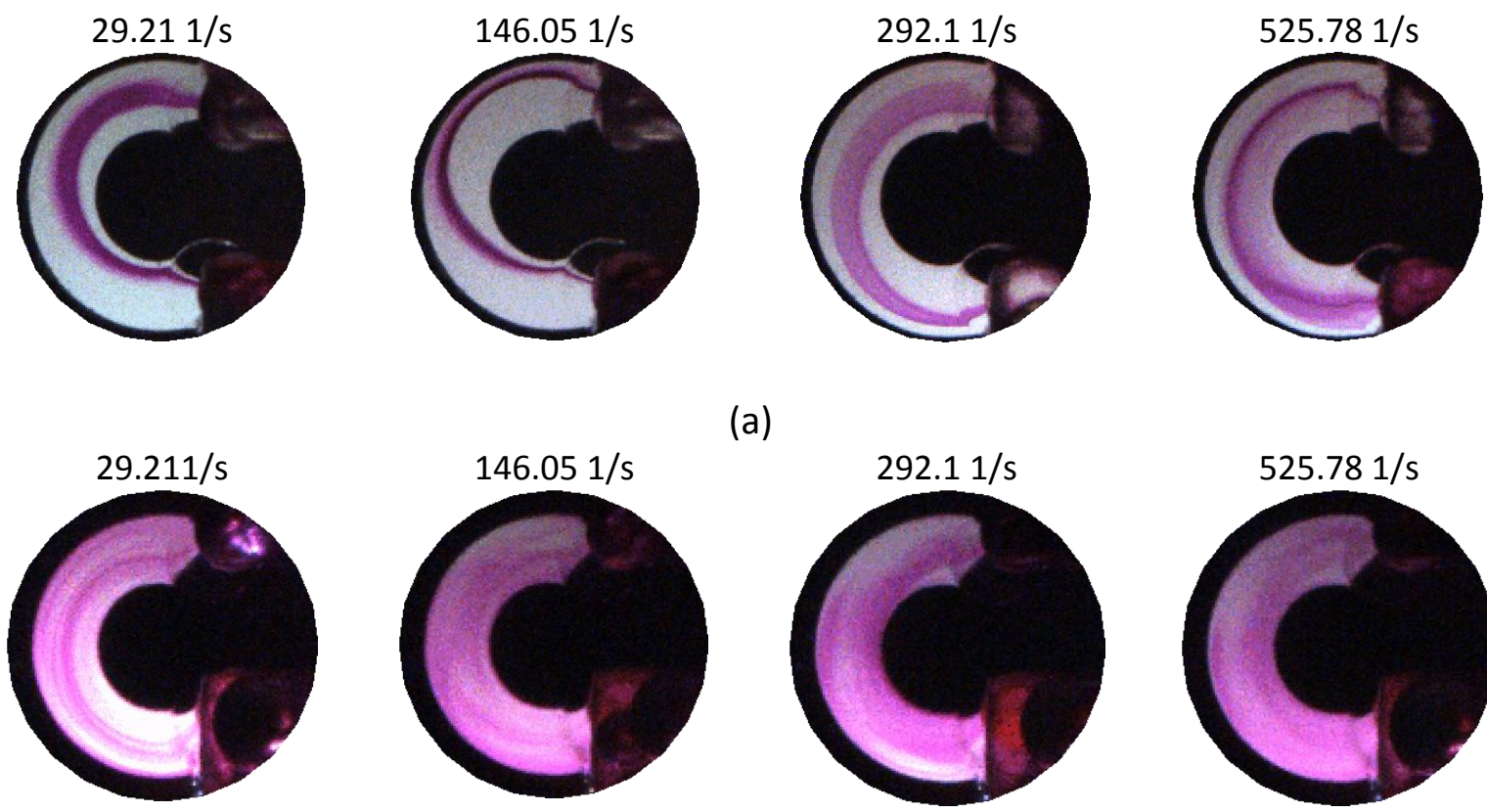

(a)
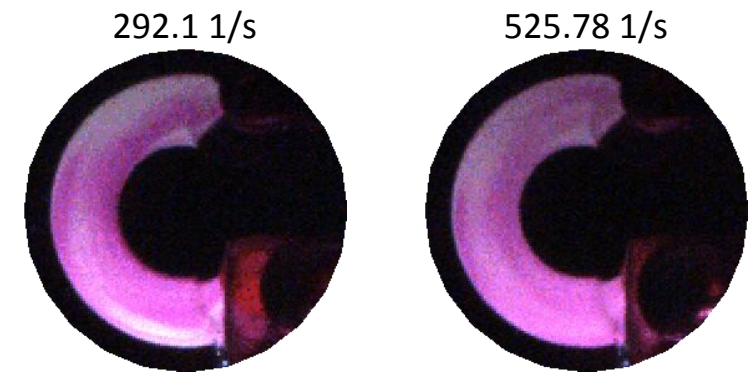

(b)

Figure 7. Flow visualization images. (a) Boger fluid solution with sucrose only (and no polymers) at rotational speeds $\Omega$ at 100 RPM, 500 RPM, 1000 RPM, 1800 RPM and shear rates at 29.21 1/s, $146.051 / \mathrm{s}, 292.1$ 1/s, 525.78 1/s. (b) $100 \mathrm{ppm}$ polymer solution at rotational speeds $\Omega$ at 100 RPM, 500 RPM, 1000 RPM, 1800 RPM and shear rates at 29.21 $1 / \mathrm{s}, 146.051 / \mathrm{s}, 292.11 / \mathrm{s}, 525.781 / \mathrm{s}$. The viscous disk pump chamber height is $640 \mu \mathrm{m}$ for all cases. 


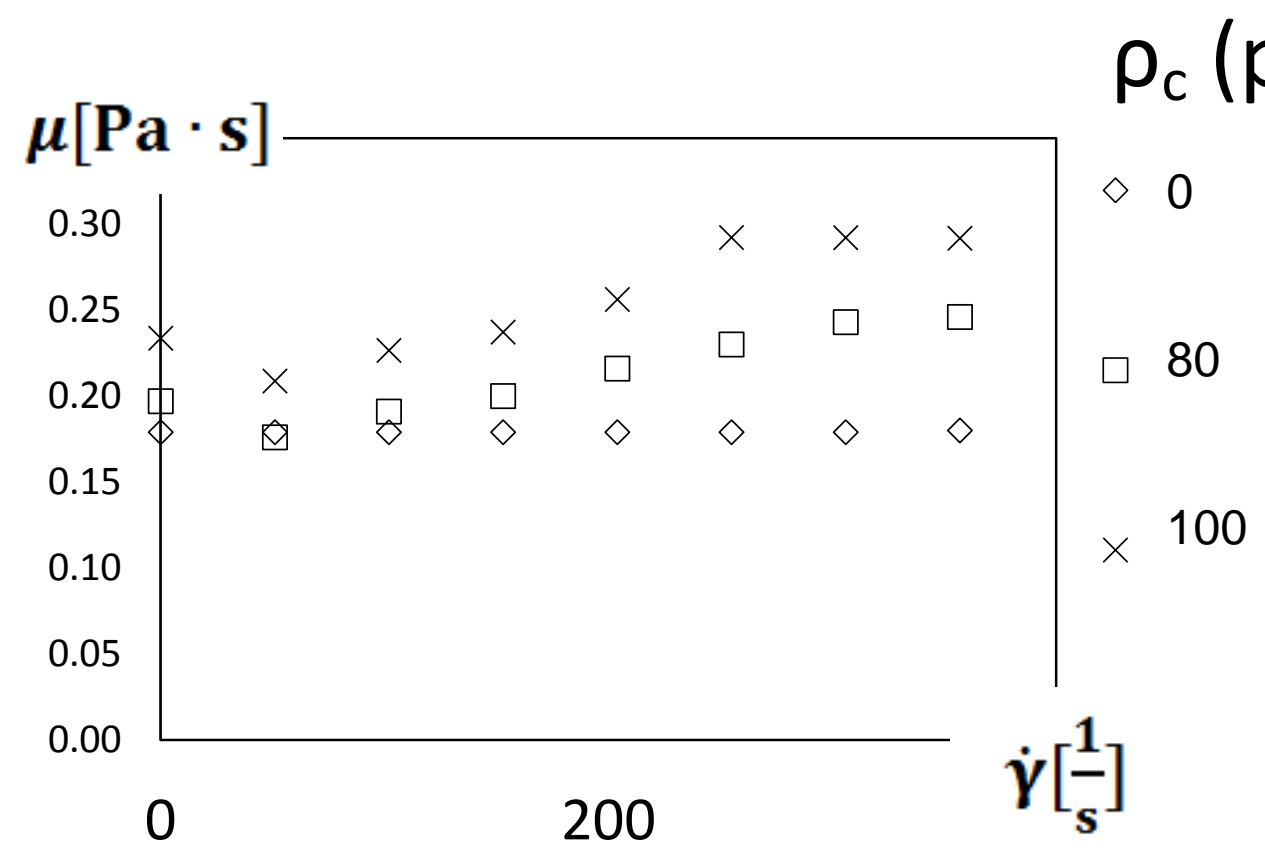

Figure 8 . Viscosity variation with shear rate for combination sucrose and polymer solutions with polymer concentrations of $0 \mathrm{ppm}, 80 \mathrm{ppm}$ and $100 \mathrm{ppm}$, for a fluid temperature of $20^{\circ} \mathrm{C}$. 


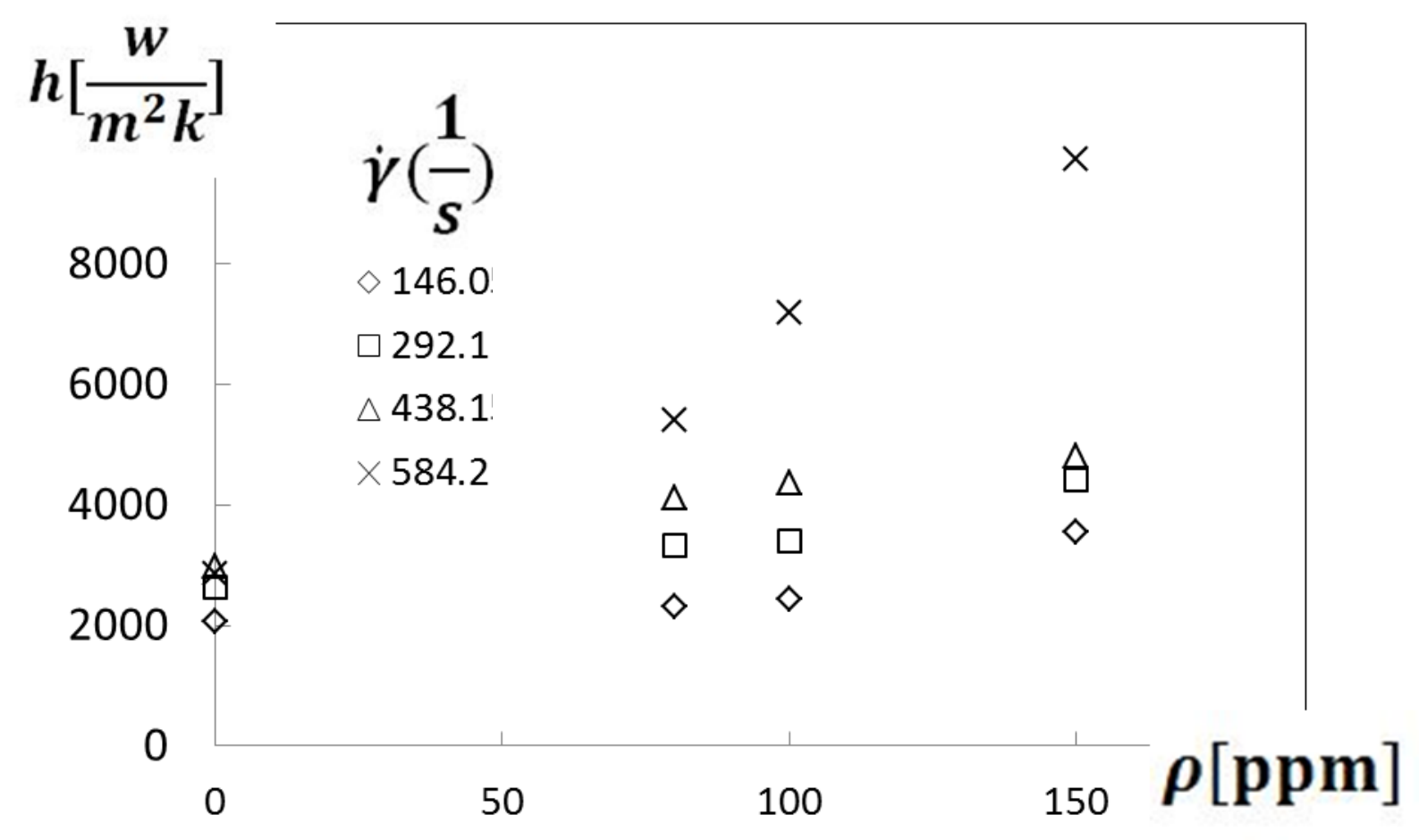

Figure 9. Heat transfer coefficient for the viscous disk pump as dependent upon polymer concentration and overall shear rate. 


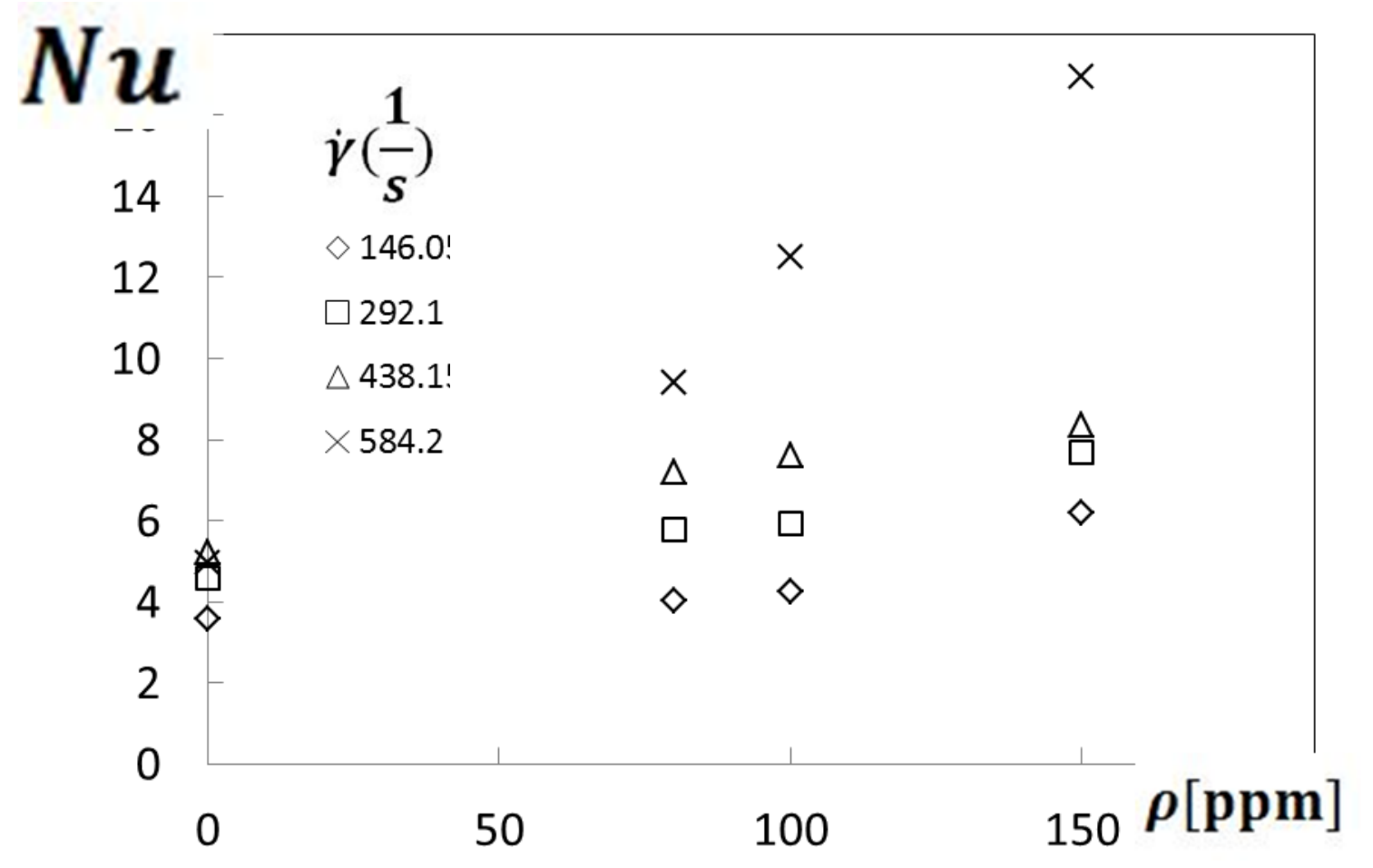

Figure 10. Nusselt number for the viscous disk pump as dependent upon polymer concentration and overall shear rate. 


\section{$\mathrm{Nu}$}

$\overline{N u_{0}}$

2.5
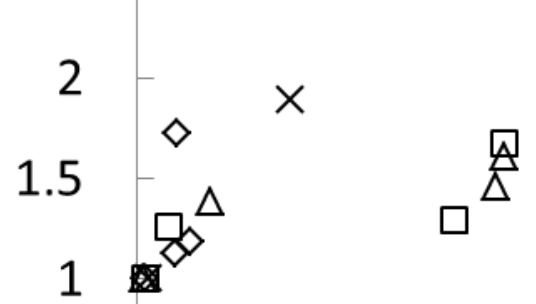

$\triangle$

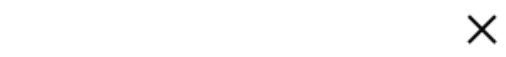

$\times$

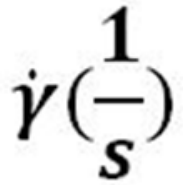

$\diamond 146.0$ !

$\square 292.1$

$\triangle 438.1$

$\times 584.2$

\section{1}

0.5

0

0

0.5

1

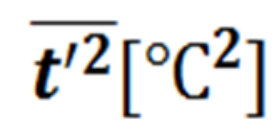

Figure 11. Nusselt number ratio variation with mean square magnitude of fluctuating temperature and overall shear rate to illustrate connection between heat transfer augmentation and chaotic flow motions. $\mathrm{Nu}_{0}$ denotes the Nusselt number for the Boger solution, or the pure sucrose solution with 0 ppm polymer concentration. 


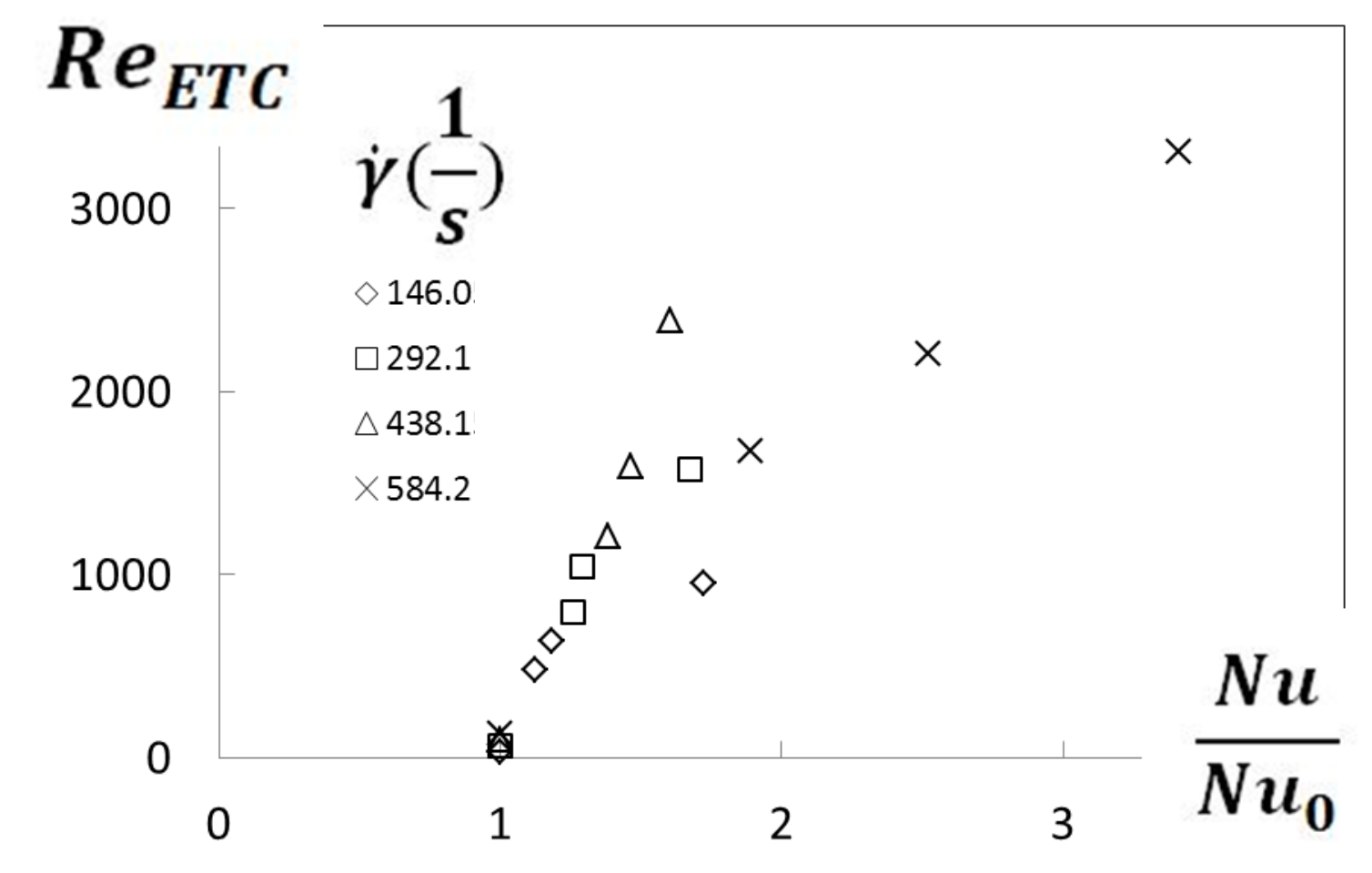

Figure 12. Variation of elastic-turbulence-concentration Reynolds number with Nusselt number ratio and overall shear rate. $\mathrm{Nu}_{0}$ denotes the Nusselt number for the Boger solution, or the pure sucrose solution with $0 \mathrm{ppm}$ polymer concentration. 